\section{Prostanoids as anti-inflammatory therapy: separating the good from the bad}

\author{
Alan J Knox
}

Prostanoids are important endogenous signalling molecules that are produced locally both physiologically and in inflammatory diseases and have potent effects on a number of inflammatory processes. Endogenous prostaglandin production consists of several stages: conversion of membrane phospholipid to arachidonic acid via phospholipase $\mathrm{A} 2$, conversion of arachidonic acid to $\mathrm{PGG}_{2}$ by cyclo-oxygenase (COX), a peroxidase reaction to produce $\mathrm{PGH}_{2}$ and then conversion of $\mathrm{PGH}_{2}$ by specific synthases and isomerases to $\mathrm{PGE}_{2}, \mathrm{PGI}_{2}, \mathrm{PGF}_{2 \alpha}$ or $\mathrm{PGD}_{2}$. COX is present in most cells, and it is the synthase/isomerase complement of the cell that determines the balance of prostanoids produced by a given cell type. Inflammatory cells tend to produce $\mathrm{PGD}_{2}$ and $\mathrm{PGF}_{2 \alpha}$, whereas airway structural cells such as smooth muscle (airway and vascular), fibroblasts, endothelial and epithelial cells produce an abundance of $\mathrm{PGE}_{2}$ or $\mathrm{PGI}_{2}$.

In contrast to $\mathrm{PGD}_{2}$ and $\mathrm{PGF}_{2 \alpha}$, which are predominantly pro-inflammatory, $\mathrm{PGE}_{2}$ is predominantly antiinflammatory. ${ }^{2} \quad \mathrm{PGE}_{2}$ inhibits acetylcholine release from parasympathetic nerve endings, mast cell mediator release and cellular responses in eosinophils, macrophages and $\mathrm{T}$ lymphocytes in vitro. Inhaled $\mathrm{PGE}_{2}$ inhibits a number of bronchoconstrictor challenges in patients with asthma in vivo including metabisulphite, ultrasonically nebulised water, exercise and allergen. A role for endogenous $\mathrm{PGE}_{2}$ has also been implicated in the refractory period, which occurs after bronchoconstrictor challenge in asthma. Everything $\mathrm{PGE}_{2}$ does is not beneficial, however. Although it relaxes airway smooth muscle at low concentrations, it can cause contraction at higher concentrations in vitro. ${ }^{2}$ When given to patients with asthma in vivo, it also causes a cough, which would limit its potential

Correspondence to Professor Alan J Knox, Division of Respiratory Medicine and Nottingham Respiratory Research Unit, University of Nottingham, Clinical Sciences Building, NUH (City Hospital Site), Hucknall Road, Nottingham NG5 1PB, UK;

alan.knox@nottingham.ac.uk usefulness as a therapeutic antiinflammatory agent as does its relatively short half-life.

$\mathrm{PGE}_{2}$ acts on four different G-protein-coupled receptors $\mathrm{EP}_{1-4} \cdot{ }^{3}$ Both $\mathrm{EP}_{2}$ and $\mathrm{EP}_{4}$ are coupled through adenylate cyclase to increases in cAMP, suggesting that these receptors are likely candidates for the bronchoprotective effects of $\mathrm{PGE}_{2}$. In contrast, $\mathrm{EP}_{1}$ and $\mathrm{EP}_{3}$ receptor activation is associated with mobilisation of intracellular calcium via phospholipase C $\beta$ and/or Gi-mediated inhibition of adenylyl cyclase. There are PGE analogues in development, which selectively target different prostanoid receptor subtypes. In order to exploit the beneficial properties of $\mathrm{PGE}_{2}$ therapeutically, a greater understanding of the pharmacology of prostanoid receptor subtypes is required in order to tease out the receptors responsible for the beneficial compared with the detrimental effects of $\mathrm{PGE}_{2}$.

The study by Birrell et al in this issue of Thorax ${ }^{4}$ sets out to try and do this by using a range of cell-based assays and in vitro models to identify the EP receptor mediating the anti-inflammatory actions of $\mathrm{PGE}_{2}$ in the lung. Previous work has suggested that the bronchodilator properties of $\mathrm{PGE}_{2}$ in human airways are mediated via activation of the $\mathrm{EP}_{4}$ receptor, ${ }^{5}$ whereas the undesirable triggering of airway sensory nerves appears to be mediated by the $\mathrm{EP}_{3}$ receptor. ${ }^{6}$ An advantage of the study by Birrell et al is that they profiled the inflammatory status of the EP receptor knockout (KO) mice in an array of preclinical respiratory disease model systems: an endotoxin model to mimic innate immune responses, an allergen asthma model and a cigarette smoke chronic obstructive pulmonary disease model.

In the lipopolysaccharide and allergen models, inflammatory cell infiltration was significantly increased in the $\mathrm{EP}_{4}$ receptor $\mathrm{KO}$ mice (with no change in $\mathrm{EP}_{1-3} \mathrm{KO}$ mice) compared with the wild-type control, suggesting a protective role for $\mathrm{EP}_{4}$ receptor activation. Similar findings were seen with regard to inflammatory cell infiltration into the airway in the cigarette smoke challenge model where absence of the $\mathrm{EP}_{4}$ receptor enhanced the inflammatory response. Collectively these studies in a range of mouse model systems provide compelling evidence that $\mathrm{EP}_{4}$ is the dominant anti-inflammatory EP receptor at least in the mouse.

In parallel with the studies in $\mathrm{KO}$ mouse models, they performed additional studies in vitro in mouse and human cellbased assays using cytokine production as a read-out and treating cells with a range of available EP receptor selective pharmacological agents and came to similar conclusions, namely that the $\mathrm{EP}_{4}$ receptor was the dominant anti-inflammatory prostanoid receptor. As cAMP, the main intracellular second messenger associated with the $\mathrm{EP}_{4}$ receptor, can stimulate different intracellular signalling proteins, the main two being protein kinase A (PKA) and exchange protein directly activated by cAMP (EPAC), ${ }^{7}$ Birrell's studies also explored which were involved in their cell systems downstream of cAMP elevation. They found that PKA but not EPAC were implicated in the $\mathrm{EP}_{4}$ receptor effects.

It will be interesting to extend studies with selective prostanoid receptor agonists to man as these agents undergo further development. Unfortunately, things may be more complex in human lung diseases than in the mouse models. We have previously shown that pro-inflammatory stimuli such as interleukin- $1 \beta$ can downregulate $\mathrm{EP}_{4}$ receptors in airway epithelial cells in vitro. ${ }^{8}$ If this occurs in these and other lung cell types that contribute to airway inflammatory diseases in vivo, it might potentially limit the effectiveness of $\mathrm{EP}_{4}$-directed therapies. However, inflammation can also interfere with $\beta_{2}$ adrenoceptor signaling, ${ }^{9}$ and this has not stopped these drugs been used widely and effectively to treat airways diseases. The study by Birrell et al is thus of major interest and may help direct prostanoidbased therapeutic approaches selectively targeting the $\mathrm{EP}_{4}$ prostanoid receptor for lung diseases in the future.

\section{Competing interests None declared.}

Provenance and peer review Commissioned; internally peer reviewed.

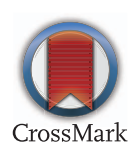

To cite Knox AJ. Thorax 2015;70:711-712.

Accepted 1 June 2015

Published Online First 17 June 2015 


\section{Editorial}

\section{(5) Linked}

http://dx.doi.org/10.1136/thoraxjnl-2014-206592

Thorax 2015:70:711-712

doi:10.1136/thoraxjnl-2015-207317

\section{REFERENCES}

1 Pang L, Pitt A, Petkova D, et al. The COX-1/COX-2 balance in asthma. Clin Exp Allergy 1998;28:1050-8.
2 Pavord ID, Tattersfield AE. Bronchoprotective role for endogenous prostaglandin E2. Lancet 1995;345:436-8.

3 Foudi N, Gomez I, Benyahia C, et al. Prostaglandin E2 receptor subtypes in human blood and vascular cells. Eur J Pharmacol 2012;695:1-6.

4 Birrell MA, Maher SA, Dekkak B, et al. Antiinflammatory effects of PGE2 in the lung: role of the EP4 receptor subtype. Thorax 2015;70:740-7.

5 Buckley J, Birrell MA, Maher SA, et al. EP4 receptor as a new target for bronchodilator therapy. Thorax 2011:66:1029-35.

6 Maher SA, Birrell MA, Belvisi MG. Prostaglandin E2 mediates cough via the EP3 receptor: implications for future disease therapy. Am I Respir Crit Care Med 2009;180:923-8.
7 Parnell E, Palmer TM, Yarwood SJ. The future of EPAC-targeted therapies: agonism versus antagonism. Trends Pharmacol Sci 2015;36:203-14.

8 Clayton A, Holland E, Pang L, et al. Interleukin-1 beta differentially regulates beta2 adrenoreceptor and prostaglandin E2-mediated cAMP accumulation and chloride efflux from Calu-3 bronchial epithelial cells. Role of receptor changes, adenylyl cyclase, cyclooxygenase 2, and protein kinase A. J Biol Chem 2005;280:23451-63.

9 Pang L, Holland E, Knox AJ. Role of cyclo-oxygenase-2 induction in interleukin-1 beta induced attenuation of cultured human airway smooth muscle cell cyclic AMP generation in response to isoprenaline. $\mathrm{Br} / \mathrm{Pharmacol}$ 1998:125:1320-8. 